\title{
Is History Real? A Cautious Answer
}

\author{
Ruei-Hong Tang \\ History of Department, Chinese Culture University, Taipei, Taiwan \\ Email: ping wentang@yahoo.com.tw
}

Received 8 July 2014; revised 9 August 2014; accepted 18 August 2014

Copyright (C) 2014 by author and Scientific Research Publishing Inc.

This work is licensed under the Creative Commons Attribution International License (CC BY).

http://creativecommons.org/licenses/by/4.0/

c) (7) Open Access

\begin{abstract}
This paper cautiously affirms history as real, in three stages: we begin, 1) by briefly reviewing the historical swings between the objective view of history and the relative view of history, followed by, 2) our careful inquiry into how history is composed by "I", "here", and "now" spontaneously spreading in time, and finally, 3) in the light of this consideration we argue for our cautious answer, "history is real", as 4), we define "caution" and "real".
\end{abstract}

\section{Keywords}

\section{History, Real, Caution, Humanity}

\section{Introduction}

This paper, though brief, is boldly cautious in affirming history as real. This paper goes in three stages: we begin, 1) by briefly reviewing the historical swings between the objective view of history and the relative view of history, followed by, 2) our careful inquiry into how history is composed by "I”, "here”, and "now" spontaneously spreading in time, and finally, 3) in the light of this consideration we argue for our cautious answer, "history is real” as 4), we define “caution” and "real”.

\section{Swings between Objectivism and Relativism in "History"}

"Reason itself is historical." This is an established view among some historians. This is because reason is the process of reasoning in dialogue dialectical, and the human process is history. Other historians take this sort of historicism as an attack on the objective timeless truth in universals and laws beyond historical flux. Historians thus quite often sway between history as objectively real and history as subjectively relative if not whimsical. Novick typifies their usual objectivism-relativism swings by describing a hundred years of history of historiography in the USA, in four stages (Novick, 1988).

In the first stage that stretched back to the Renaissance days, historiography focused on historical truth in historical objectivity. History produces the past "as it had actually occurred," as it reflected the intentions of the 
agents, developed in the sequence of time. In the second stage between World War I and World War II, this alleged objective stance is criticized as itself historically relative in the flux of time, as advocated by Charles A. Beard and Carl L. Becker, in the perspectives and frames of reference determined by shifting social conditions and various existential factors.

In the third stage between World War II and Cold War, this stance is itself criticized as sheer subjectivism, unable to obtain absolute objectivity of things as they are in themselves, and thus "objective truths" in history reemerged to shape the content and structure of history. In the fourth stage after 1960, there appears confusion of values. Many conflicting ideas and ideals came up in radical skepticism, to destroy assured stances in history both objective and relative.

Looking back, we realize how much we have swung back and forth between two unreasonable poles, stable objectivism on one hand, and subjective relativism, on the other. Objectivism is beyond history; the objectivists demand of history something not history; such demand is unreasonable. All this while, the objectivists ridicule the relativists as subscribing to "historicism" that is doubly ironic and self-contradictory, for this reason.

This epithet, historicism, hurled at subjectivism by objectivism, intuitively ascribes whimsical subjectivity to history, to show that the objectivists themselves [a] know that history is so fickle as to induce subjectivism, while [b] fully knowing that history is in the past far out there away from us, not at all subjectivity intimate here now. Thus either pole fits no history. No wonder, our historiography today is in a chaotic mess, bankrupt without a single coherent ideology. Everything is in the whirlwind of brute time.

Let us push the whole mess in this negative fashion and direction to its bitter end. Since we are part of history, in fact the basic launch-pad that begins history, if we ever judge history arbitrary, then the "arbitrary history" renders us ourselves arbitrary, and now this whole business of "the arbitrary judge judging history arbitrary" is itself arbitrary. Nothing is then not-arbitrary, and the entire process of judging things collapses into nonsense. Thus history simply can not be arbitrary at all. History is the necessity of our living at all, and so history must exist somehow, whatever it is.

But, then, we must beware. What is history? We see we are confronted with three incredible impossibilities, history as arbitrary, history as objective beyond history, and history as subjective, mired in relativism. We must approach history with extreme caution ${ }^{1}$, in three negations, i.e., history is not arbitrary, not objective, and not subjective. Then, we must repeat our question, “What is history?" This inevitable question leads us to the next section.

\section{Three Obvious Conditions in Common Actuality, I, Here, and Now}

First, let us push this radical doubt of history for a while before affirming history. In this radically confusing situation, we notice three obvious conditions in our common actuality, the conditions that, we come to realize, compose history. But these conditions first lead us to doubt the very possibility of "real" history even before considering "how" real history is.

These conditions are three, the "I," "here," and "now" as, each, one and many. And then, we come to realize that these three common features are the fluid components, after all, of history and of the historicity of the very notion of "fact" itself. An explanation is needed, in three points.

First, history begins at the self, for without me myself, there would be no history. But the "I" is quite odd; it is one and many. My claim of "I" is by myself alone, but "I" is also claimed by every other self as "I," quite many and different. This protean "I" generates the "now" sensed as so many "then," as my "now" now is not your "now" then, and generates the "here" sensed as so many "there," as my "here" here differs from your "here" there ${ }^{2}$. These same differences bespeak the spontaneous spread; such a spread, all around in time, of "I," "here," and "now" composes history to conversely compose our self-integrity.

Second, the "I" here and now spreads to compose a "we" social in time. History is composed of our shaping-now of historical documents in our hand, now. History is made of two factors, then, our decision and our decision now. History is contemporary and radically social in time, back and forth. This point is intimated by Collingwood's assertion that history is a re-enactment, acting again now what has happened in the theater of our

\footnotetext{
"“Caution” itself will be cautiously elucidated to clinch this whole essay.

${ }^{2}$ See Demonstratives, ed. Palle Yourgrau, Oxford University Press, 1990; it has an interesting collection of essays. Richard M. Gale, "Indexical signs, egocentric particulars, and token-reflexive words,” The Encyclopedia of Philosophy (1967), ed. Paul Edwards, NY: Macmillan, 1972, 4:151-155. These Western logicians never noticed "history" generated by I, here, and now, however. Western logic is sadly no-history at all.
} 
living on. And we must be alerted further. Both our decision and our decision now are constantly changing, themselves historical.

Third, since time immemorial, we humans have been in quest of "fact" against fiction, but this "fact against fiction" itself is historical, in constant shift. Subsequent generations censored Homer as inflating a common battle into the legendary "Trojan War." Confucius' famous approval of "composing history" by historians at the time shocked even the seasoned Sinologist Watson today, as doctoring "facts" ${ }^{3}$. Watson's shock loudly proclaims how much today's view of historical "fact" has shifted from Confucius' days.

Thus, history composed of "I," "here," and "now" are one and many, we and our decisions now that compose history are themselves historically uncertain, and the basis of history, "facts," are themselves historically swinging quite uncertain. How can history be one and many, its components our decisions and "fact" so uncertain, and still be "history"? We cannot help but sigh with Aristophanes ${ }^{4}$ that brute swirling whirlwind of time has dislodged, no, smashed asunder, Zeus the supreme stable laws of reality, including the reality of history governing everything. Everything orderly is smashed asunder to scatter in the whirlwind.

Let us repeat this woeful fact of no-fact. Everything is whirlwind un-historical, even the very standard of historical factuality is in the whirlwind of time if not the whirlwind itself, and so the so-called "facts" just scatter with dead leaves in the storms of time. History depends on us now who are changing ourselves. History is itself radically historical. History is the whirlwind of time that sweeps away orderly history.

\section{Does "Anything Go"? Do We Have No Solid Real History Now?}

\subsection{Three Reversals}

Naturally, we cannot help but wonder. "We are now surprised. Does all this mean that 'anything goes'? Do we now have no solid real history to speak of?” But, then, have we noticed it? Here are three strange reversals, and these reversals strangely revive history out of its own ashes.

First, this view, "No history," implied in the rhetorical questions here, "Does anything go? Don't we have no real history?" is itself historical, and so if history is nonexistent, then this view destroys itself. We must closely inquire into what is going on here, and we then shall find that the radical self-destruction itself radically reconstructs history. History is a Phoenix rising from its own ashes, again and again.

In addition, as we look back on the Section 2 above that seems to lead us to historical nihilism, we notice that its second point says that history has two bases, the subjective "I" and the "now." History is we, contemporaneous with us now; if history is arbitrary, we are, too, here now. Such conclusion is inevitable and yet incredible, destroying even all our negations themselves that arise from us. As we are put asunder, history is destroyed, and as history is put asunder, we are destroyed.

And then, thirdly, even our negations are nowhere. As we deny history, we deny ourselves, and our very denial is itself destroyed. So, we realize that, on the contrary, we and now must be both solidly certain. Every act of our thinking, even every doubt of ours-and so, history itself a collection of all our thinking-must launch out from this solid base, we here now, which is the launch-pad of history; we here now is history itself. We must then claim now, "history is real," as real as we are now, but with cautions infused by so many considerations above.

\subsection{Our Five Cautions}

How do we caution ourselves about history? We must be cautious on no less than five counts. First, we assert now that such and such are historical facts, while we would caution ourselves that our asserted "facts" may well turn out fictive, in the judgment of the later generation, whose opinions will in turn be judged by an even later generation. Judgments on facts are themselves historical, and so "facts" sway in historical vicissitudes.

Look. We were absolutely sure that metal never floats or flies; now metal planes and metal ocean liners are routinely flying and daily floating. As a "fact"-yesterday, metal did not fly or float, but as a "fact"-today, metal do routinely fly and float. So, the "fact" yesterday is a fiction today, and so we had better be prepared—cautious-

\footnotetext{
${ }^{3}$ Indictment of Homer is well-known. Thucydides says that his history "will not be disturbed by a poet exaggerating his craft” (1.21), clearly referring to Homer. Plato finds fault with the lack of morality in popular Homer. On today's complaint on Confucius, see Burton Watson, tr., The Tso chuan: Selections from China's Oldest Narrative History, NY: Columbia University Press, 1989, pp. 79-80.

${ }^{4}$ Aristophanes sighed, “Whirl is King, having driven out Zeus,” in his Clouds, line 379, through the mouth of Shepsiades.
} 
that our "facts" today may well turn into fiction tomorrow. We must be cautious about what we regard as "solid facts" now. "Facts" themselves are historical.

Secondly, remember this important point also. Such cautious decisiveness of ours now is itself historical. "History is real” this cautious way all around. And "caution" itself must be cautioned. Caution here means critical skepticism, as both skepticism and criticism mean alike, i.e., as discerning inquiry ${ }^{5}$. They are invincible, we must note, for we cannot be skeptical about skepticism without joining it, nor can we criticize criticism without joining it. Thus our cautious assertion, "history is real," is invincible, quite correct all around.

Thirdly, still, "Yes, history is real" sounds as if it were uttered by a Pollyanna overconfident. We must now, then, take a careful look at the cautious shape history-as-real assumes. We are told above that history is made of "we now shaping the past," but our "now" is brutally blown, tossed and scattered about, by the brute whirlwind of time, and all heads and tails are uncertain, without a single coherent frame to go by.

But once we look back, things begin to take shape, and the look-back is history. The dead people are easier to discern, as the dust now settled later shows what has been what. We are thus wiser after the fact. But we are "wiser" (after the fact), not all-wise, as we are always subject to corrections by subsequent generations looking back at us. Thus, surprisingly, we have hope in this continuous process of mistake-making and mistake-correcting.

History is structured as such a retrospective process of correction, as "world happenings are world-corrections" (Hegel), and so in this sense, history makes no mistakes as it continues to correct itself, for self-correction ciphers assurance of making no mistake. "History making no mistakes" is another way of expressing "history is real" in a dynamic and invincibly cautious sense. "Yes, history is real" is thus not pronounced by a Pollyanna at all; it is a fully cautious and convincing answer, quite invincible.

Fourth, someone still mumbles, "A specific culture flourishes according to its specific cultural taste, no one can argue about taste, and so 'fact,' 'cosmology,' etc., of a former age cannot be evaluated by later ones; no progress is possible, and Hegel is wrong." Well, we have seen that the metal-fact of yesterday (metal does not fly) is no metal-fact of today (metal flies), as the science of space (aerodynamics, aeromechanics) progressed, and progress is history. History does make progress. But what about "taste"? Isn't history a progress in tastes, which is senseless?

The "taste of a culture" is not floating around spineless; the so-called "cultural taste" actually serves as a paradigm that structures a specific viewpoint on attitudes toward our common life world. Culture combines attitude (taste) and viewpoint (structure). Such attitudinal paradigm has constantly been detected and criticized by later generations as "inadequate"; Newton’s paradigm criticized the Aristotelian, as Einstein's did Newton's, Hawking's did Einstein's, etc., and so progress of a sort has been made in a specific area of cultural taste, called science.

Likewise, critiques do also exist even in the more diffused world of aesthetic taste, such as painting, literature, music, and even philosophy. We see these criticisms in any "history of art" and "history of thought" in the West, in Japan, in India, in China, etc. Tapestries of genres exist side by side, as each criticizes others as others criticize each as "Marxist," "economic," "deconstructionist," etc., while cultural chauvinism surprisingly creeps in ${ }^{6}$. Histories of art and of thought do get progressively subtler and more sophisticated, and the progress is history. Thus, history does progressively correct itself.

Fifth, still, continual self-correction implicates continual mistake-making. Thus history is bipolar, error-prone and error-free, Janus-faced, though we hope history goes forward toward the direction of error-elimination in self-correction. Our hope may be precarious, we are not a Pollyanna, but this hope can never be totally eliminated, as we are forever ashamed of dictators and Hitlers, never proud of them as they continue to prop up in history to our shame. Now, to be aware of all this bipolarity and our decisive facing toward self-correction, this decisive awareness of ours ciphers our human dignity in all its cautious decisiveness. "History is real" remains our cautious and decisive declaration in human dignity.

\footnotetext{
${ }^{5}$ The Oxford English Dictionary, 2nd Edition (1991), Clarendon Press, Oxford, 2001, says, "sceptic” is inquiring (XIV: 609), “critic” is decerned, judge (IV: 29), and “decern” is discern (IV: 328).

${ }^{6}$ Countless cultural histories of arts and thoughts are too many and famous to cite. On the last point of cultural chauvinism, see, e.g., Kuang-ming Wu’s “'Let Chinese Thinking Be Chinese, Not Western’: Sine Qua Non to Globalization,” Dao: A Journal of Comparative Philosophy, June 2010, pp. 193-209, and "Western as 'Global'-American Studies of Chinese Paintings: A Review of Stones from Other Mountains: Chinese Painting Studies in Postwar America, ed. Jason C. Kuo, Washington, DC: New Academia, 2009,” Journal of Chinese Philosophy, September 2010, pp. 499-501.
} 


\section{A Round-UP}

We must now brave the price of repeating what has been said above, to alert ourselves on five more points in relation to history. Such cautious alert serves to round up this whole essay.

To begin with:

The "one and many" in the I, the hear, and the now is a killer, we think. How could any one thing be both "one" and "many"? Well, the one thing here is a situation in progress in time, each situation always complete in itself yet shifting ever different, only half-done. Master logician Whitehead caught it when he quipped that all truths are half-truths ${ }^{7}$. Wow! What does it mean?

Each truth is true in itself while incomplete, complete in itself while expanding in this direction and then in that, in this perspective and then in that. "History" is such shift of "and then," in time in perspective. History is a dynamics of complete yet half truths shifting, in one kaleidoscope of "one and many" now, and then in another kaleidoscope of "one and many" another "now," and these "and" in space are "and" in time-shifting as well, ever one and many.

History is thus one fascinating kaleidoscope in time of many kaleidoscopes in space, an "and"-dynamics of spatiotemporal "one and many." One view of one time is exposed as a "half truth" in the subsequent view, which in turn turns out to be a new "half truth" another time later. History is a dynamics forever of complete halves each time, on and on. Mother Nature that nurtures us, embracing-moistening us, is in this manner all-alive, showing here complete face one way, half-way, here now, and then another total face another way, half-way, here now again later.

A fascinating portrayal of these enthralling dynamic shifts is "history" envisaged here now, then envisaged again "here now" later, on and on. The half-truths are all-true all alive as Mother Nature is alive as history-dynamo. History is Mother Nature alive envisaged by us alive through one generation after another, each history complete only to turn out half true later, each time in each later generation. Such is history forever alive.

Next:

We ask, "We see that this paper here is historical in the above manner, but is this paper one of historicism?" Well, No, if historicism takes history as a pure object out there to consider separately from us. No, again, if we take historicism to mean uncertain subjectivism attributable to history. But, Yes, if historicism means history, whatever it is, that confronts us from beyond us while originating in us. But to ward off possible misunderstanding, we had better say that this paper insists that history is real, as above described in dynamic time sequence.

Three:

We overhear someone mumbling, "So what? Who cares whether history is real, or if it is unreal? We are too busy for such idle debate.” Unfortunately, this move plunges us straight into a disaster, for this simple inevitable reason. History is our own living that lasts generation after generation. So, history as real makes us real. Neglecting the history that realizes us, we neglect to realize us, to turn us unreal and hollow, however much we huff and puff to engage in our business here now. All our living activities are swept into the dustbin of unreality, as soon as we bypass history as real.

Four:

The converse point to above holds soberly valid as well. To solidify our living authentic—real and solid—we must learn from history on how we have behaved in the past to harvest what results. History charts us, often via its record of past failures, away from pitfalls of our projects and their implementations. Thus, not remembering the past condemns us to repeat it, as Santayana reminds us, and the repetition shall be disastrous.

In contrast, if we carefully learn of failures that resulted from project A and our struggles to implement it, we must chart our life in project not-A, either straightly denying A, or adopting variously adjusted alternatives to A, or both, and that in a different mode of struggling for our ideal, different from what has been tried in the past. All in all, "history is real" is thus loaded with vitally practical significance for us today here now, never to be taken lightly, much less bypassed with disdain. "Who cares for history?” We must all, each in our own ways, care for history.

But, five, what is "real"?

From what is said above, we realize that what is real is, in us or outside us, what confronts us as we shape it,

\footnotetext{
${ }^{7}$ See Dialogues of Alfred North Whitehead (1954), Boston: David R. Godine, 2001, pp. 14, 250, 274, and 298. Someone may ask Whitehead whether Whitehead's statement is itself half truth or not. Whitehead would retort that "that asking” is itself asking for the whole "half truth" quipped by Whitehead. "Half truth" is a dynamo of such dialogues on and on.
} 
what shapes us as we shape it. Such interactive definition of "real" sounds spooky, but it is concrete, detailed, and comprehensive enough to cover both our science and our history, and allows us to realize that the invisible history is mother of the visible science.

\section{Conclusion}

We call this "mother" Mother Nature that is inside us and out, amply deserving of our historical reverence, to the good of our Mother Nature throughout history, to redound to our own good throughout history. Our reverent living begins and ends at us taking history with absolute historic seriousness. History is eminently real in Mother Nature eminently real, to make us eminently real. We humanity, Mother Nature, and history, these three remain forever, and the most critical of these is history eminently real. Is history real? Yes, it assuredly is, on pain of making everything hollow and unreal if history is ever not real.

\section{References}

Novick, P. (1998). That Noble Dream: The “Objectivity Question” and the American Historical Profession. Cambridge: Cambridge University Press. 
Scientific Research Publishing (SCIRP) is one of the largest Open Access journal publishers. It is currently publishing more than 200 open access, online, peer-reviewed journals covering a wide range of academic disciplines. SCIRP serves the worldwide academic communities and contributes to the progress and application of science with its publication.

Other selected journals from SCIRP are listed as below. Submit your manuscript to us via either submit@scirp.org or Online Submission Portal.
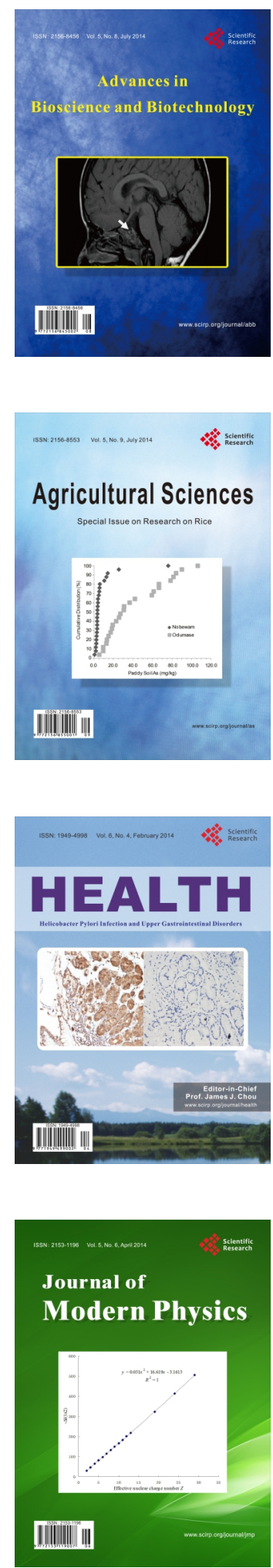
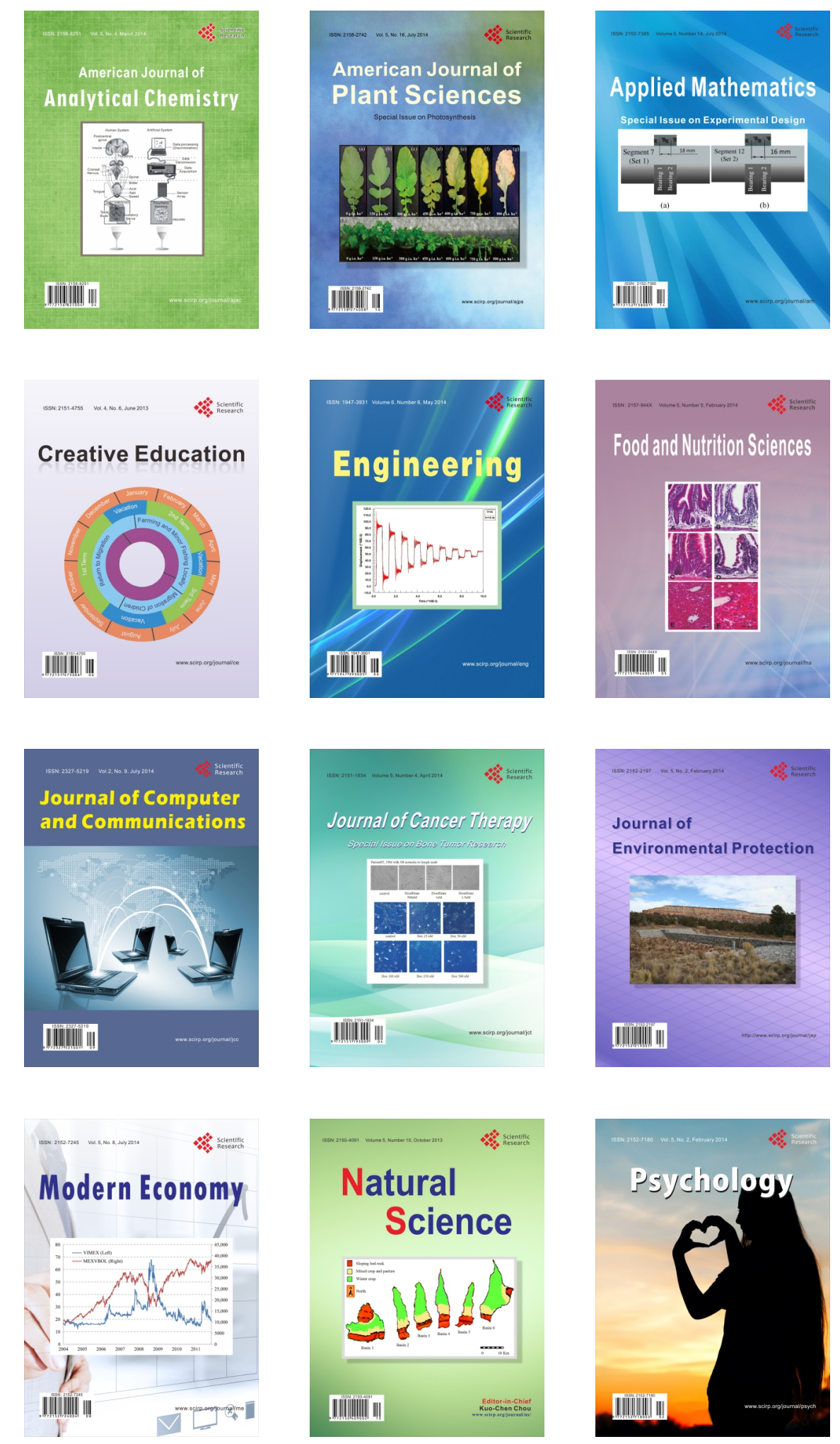